\title{
Antifungal Activity of Nor-securinine Against Some Phytopathogenic Fungi
}

\author{
Sangita Sahni ${ }^{1}$, S. Maurya ${ }^{1}$, U. P. Singh ${ }^{1 *}$, A. K. Singh ${ }^{2}$, V. P. Singh ${ }^{2}$ and V. B. Pandey ${ }^{2}$ \\ ${ }^{\prime}$ Department of Mycology and Plant Pathology, Institute of Agriculture Sciences \\ ${ }^{2}$ Department of Medicinal Chemistry, Institute of Medical Sciences, Banaras Hindu University, Varanasi 221005, India \\ (Received January 17, 2005)
}

\begin{abstract}
Crude extracts and active principles from medicinal plants have shown potential role in controlling plant diseases in glasshouses as well as in fields as one of the safest and ecofriendly methods. The effect of nor-securinine (an alkaloid) isolated from Phyllanthus amarus has been seen against spore germination of some fungi (Alternaria brassicae, A. solani, Curvularia pennisetti, Curvularia sp., Erysiphe pisi, Helminthosporium frumentacei) as well as pea powdery mildew (Erysiphe pisi) under glasshouse conditions. The sensitivity of fungi to nor-securinine varied considerably. Nor-securinine was effective against most of the fungi. $H$. frumentacei was more sensitive even at the lowest concentration $(1,000 \mu \mathrm{g} / \mathrm{ml})$. Likewise conidia of $E$. pisi were also inhibited in partially or completely appressorium formation. Pre-inoculation treatment showed greater efficacy than post-inoculation in inhibiting powdery mildew development on pea plants in a glasshouse. Maximum inhibition occurred at $2000 \mu \mathrm{g} / \mathrm{ml}$.
\end{abstract}

KEYWORDS: Antifungal activity, Erysiphe pisi, Nor-securinine, Phyllanthus amarus

Fungal diseases of plants have always been one of the major constraints in crop production causing severe losses every year. Since the very beginning of their appearance researchers have succeeded in controlling some devastating diseases by synthetic fungicides. As several synthetic fungicides are highly effective in controlling plant diseases, their negative effect on human and animal health and also on the agroecosystem was gradually realized which entailed serious research in developing alternative environmentally acceptable (environment-friendly) methods. These efforts included biological control, genetic engineering, use of systemic acquired resistance (SAR) with the help of biotic and abiotic agents (Lyon et al., 1995), and biodegradable natural products especially from medicinal plants (Prithiviraj et al., 1996).

Several workers have used crude plant extracts in vitro, in glasshouse and under field conditions against several plant pathogens with considerable success (Chakravorty and Pariya 1977; Asthana et al., 1982; Vollekova et al., 2001). Also various compounds isolated from the plants were shown to be effective against some plant pathogenic fungi in vitro (Maillard et al., 1987, 1989; Kobayashi et al., 1987; Singh et al., 1988, 1990; Prithiviraj et al., 1997a, b; Singh et al., 2001; Ameer Basha, 2002; Maurya et al., 2001, 2002), in glasshouse (Reamers et al., 1993; Singh et al., 1995) and also in the field (Prithiviraj et al., 1996, 1998; Sarma et al., 1998, 1999). The use of plant products under field conditions is rare because of their presence in small amounts in plants which is usually cost-prohibitive Neemazal, a preparation

\footnotetext{
$\overline{\text { *Corresponding }}$ author <E-mail: upneem@sify.com>
}

from neem (Azadirachta indica) and ajoene, a constituent of garlic (Allium sativum), have recently been used successfully against powdery mildew (Erysiphe pisi) of pea under field conditions (Singh et al., 1995; Prithiviraj et al., 1998).

Several alkaloids are known to affect biological functions at a very low concentration showing antimicrobial activity (Atta-Ur Rahman et al., 1997; Mahajan et al., 1982; McCarthy et al., 1992; Singh et al., 1994, 1999, 2000; Srivastava et al., 1994). (-)-Amarbellisine, a lycorine type alkaloid from Amaryllis belladonna L. showed potent antimicrobial efficacy (Evidente et al., 2004). Powdery mildew is one of the serious diseases of pea (Pisum sativvm). Several workers (Prithiviraj, 1997; Singh et al., 2000) reported the effects of a number of plant products against pea powdery mildew as well as other diseases as a unique alternative to synthetic fungicides. The present study deals with the effect of nor-securinine against spore germination of some fungi and also its effect on conidial germination and development of Erysiphe pisi conidia on excised pea leaves and on potted plants. The results are presented here.

\section{Materials and Methods}

Isolation and maintenance of fungi. The test fungi were isolated from their respective hosts collected from the experimental farm of the Banaras Hindu University (Varanasi, India) on potato dextrose agar (PDA: peeled potato $250 \mathrm{~g}$, dextrose $20 \mathrm{~g}$, agar $15 \mathrm{~g}$, distilled water $1 l$ ) medium. The cultures were further purified by single spore isolation technique and maintained by periodic 
transfer on the same medium for further experiments. Seven to ten day old cultures were used in the experiments. Erysiphe pisi was multiplied on pea plants grown in plastics pots $(90 \mathrm{~mm}$ in dia.) in glasshouse for the experiments.

Extraction and purification of nor-securinine from Phyllanthus amarus. The plant Phyllanthus amarus (Family: Euphorbiaceae) is distributed throughout India as a weed in cultivated and wastelands. The earlier literature indicated that Phyllanthus amarus has potent biological efficacy in animal system. It is widely used as anti-hepatotoxic agent in Indian system of medicine (Manske, 1973). Preliminary test of crude extract done in vitro showed high efficacy against the test pathogens, indicating that the extract has spore germination inhibitory compounds. Keeping this view, the isolation and purification of extract were done by column chromatography to isolate active ingredients. Two major alkaloids, nor-securinine and ent-norsecurinine were isolated from this plant. Antimicrobial efficacy of ent-norsecurinine has been already reported by (Mitul et al., 2002). The present experiment deals with the isolation of the compound and its antifungal activity.

The dried and powdered whole plant $(2.1 \mathrm{~kg})$ was successively extracted with petroleum ether $\left(60 \sim 80^{\circ} \mathrm{C}\right)$ and methanol in a soxhlet extractor. The solvents were distilled off on water bath, which gave greenish brown syrup of methanol extract $(40 \mathrm{~g})$. The methanol extract was chromatographed over a silica gel column eluting with solvents of increasing polarity. TLC monitored the collected eluants at every stage for their homogeneity. The similar eluants collected from $\mathrm{CHCl}_{3}-\mathrm{MeOH}(4: 1)$ were mixed together which on crystallisation from methanol furnished a mixture of two alkaloids having $\mathrm{Rf}$ values 0.50 and $0.55\left(\mathrm{C}_{6} \mathrm{H}_{6}-\mathrm{CHCl}_{3}-\mathrm{MeOH}, 4.2: 1\right)$. Preparative TLC as oil separated the nor-securinine. The nor-securinine could not be crystallised by different solvents and polymerized readily on keeping. It was then taken in methanol and ethereal $\mathrm{HCl}$ was added to it. After work up, it gave nor-securinine hydrochoride as oil. The norsecurinine was regenerated by addition of ammonium hydroxide and extraction with $\mathrm{CHCl}_{3}$, as an oil, which further did not crystallise with any solvent. It exhibited $[\alpha]_{\mathrm{D}}^{20}-268^{\circ}(\mathrm{c}, 0.42, \mathrm{MeOH})$. Its molecular formula was determined as $\mathrm{C}_{12} \mathrm{H}_{13} \mathrm{NO}_{2}\left(\mathrm{M}^{+}=\mathrm{m} / \mathrm{z} 203\right)$ from the mass spectrum. It exhibited UV $\lambda \max (\mathrm{MeOH}): 255$ and 257 $\mathrm{nm}$ and IR vmax (KBr): $1,800,1,769$ and $1,638 \mathrm{~cm}^{-1}$. The peaks in IR together with ${ }^{1} \mathrm{H}-\mathrm{NMR}$ fully supported for $\alpha$, $\beta$-unsaturated- $\gamma$-lactone unit. In ${ }^{1} \mathrm{H}-\mathrm{NMR}$ it showed a sextet at $\delta 6.4 \sim 7.0(2 \mathrm{H}, \mathrm{H}-14$ and $\mathrm{H}-15)$, a triplet at $\delta 3.63$ $(1 \mathrm{H}, \mathrm{H}-7)$, a singlet at $\delta 5.7(1 \mathrm{H}, \mathrm{H}-12)$ for ABX pattern. The high field multiplet at $\delta 1.4 \sim 2.2$ accounted for $\mathrm{H}-8 \alpha$ and $\mathrm{H}-8 \beta$ together with $\mathrm{C}-3$ and $\mathrm{C}-4$ methylene protons.

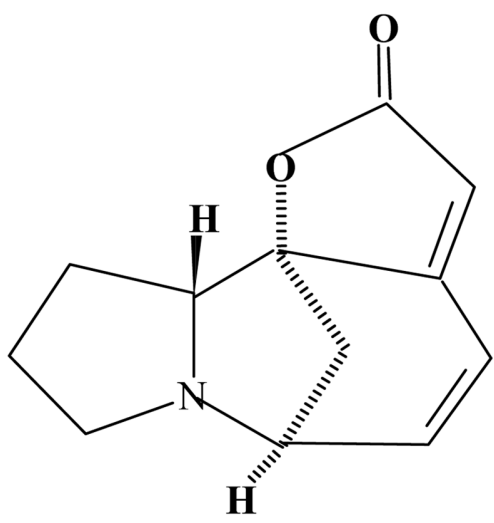

Fig. 1. Structural formula of Nor-securinine.

One of the protons in the C-5 methylene exhibited absorption at $\delta 2.2 \sim 2.8$, while C-2-H and the other C-5-H exhibited multiplet at $\delta 3.0 \sim 3.4$. These data were in perfect agreement with the reported data of nor-securinine. It was thus identified as nor-securinine (Fig. 1) (Manske, 1973). After purification and characterization of nor-securinine their biological efficacy was tested on some plant pathogenic and saprophytic fungi.

Assay of alkaloid. Stock solution of alkaloid nor-securinine $(2,000 \mu \mathrm{g} / \mathrm{ml})$ was prepared by dissolving $20 \mathrm{mg}$ of the chemical in $20 \mathrm{ml}$ of distilled water. Required concentrations $(1,000,1,500,2,000 \mu \mathrm{g} / \mathrm{ml})$ were prepared from the stock solution by diluting with distilled water. However, test concentrations were determined on the basis of their biological efficacy. It has been found that higher concentration of the active chemical (viz., 2,500, 3,000 $\mu \mathrm{g} / \mathrm{ml}$ ) showed strong fungicidal and phytotoxic activity and $100 \%$ inhibition was observed among all the test fungi, thus $1,000,1,000$ and $2,000 \mu \mathrm{g} / \mathrm{ml}$ concentrations were used to observe their biological efficacy against phytopathogens. One drop $(30 \sim 40 \mu l)$ from each concentration of the chemical was placed on grease-free glass slides. With a sterile inoculation needle, fungal spores (200 300) were picked up from 7-10-day-old growing cultures and mixed in the solution. The slides were later placed in moist chambers made by placing two sterile moist filter papers on upper surface of the lid and base of Petri plates. The plates containing the slides of spores were incubated at $25 \pm 2{ }^{\circ} \mathrm{C}$ for $24 \mathrm{~h}$. Germination was observed after staining with cotton blue prepared in lacto phenol under binocular light microscope (Nikon, Japan). Spores mixed in sterile distilled water served as control. All the experiments were conducted in triplicate. Randomized block design (RBD) for statistical significance was used for the analysis of data.

Germination and development of Erysiphe pisi conidia on detached pea leaves. Second nodal leaves from 20- 
day-old pea plants were excised with the help of sharp scissors and spread on filter paper towels. The leaves were then inoculated by Erysiphe pisi conidia on adaxial surface by tapping heavily infected pea leaves so as to get 200 300 spores per $\mathrm{mm}^{2}$ of the leaf area. These leaves were then floated on sterilized distilled water in Petri plates which served as control.

Pre-inoculation treatment. Different dilutions of the chemical $(1,000,1,500$ and $2,000 \mu \mathrm{g} / \mathrm{m} l)$ were sprayed thoroughly with the help of a hand atomizer $24 \mathrm{~h}$ prior to seeding on the excised pea leaves of 20-day old plants and then placed on filter paper towels. These leaves were later floated on distilled water keeping adaxial surface upwards. After $24 \mathrm{~h}$ of spraying, the leaves were then seeded with $E$. pisi conidia by tapping heavily infected leaves on the adaxial surface.

Post-inoculation treatment. For post-inoculation treatment, the experiments were conducted as stated above except that the spores were tapped first and after $24 \mathrm{~h}$ the chemical was sprayed by a hand atomizer on the seeded leaves which were then again floated on distilled water in Petri plates. All the pre- and post-inoculation treated leaves including control were incubated for 24 and $48 \mathrm{~h}$ at $25 \pm 2^{\circ} \mathrm{C}$. After incubation, the leaves were fixed and stained by the method of Carver and Adaigbe (1990). A pad of filter paper was placed in a Petri plate containing the fixative (Ethyl alcohol-acetic acid, $3: 1$ ). The leaves were placed on the filter paper with adaxial side up to minimize the disturbance of conidia on the leaf surface. The leaves were fixed for $48 \mathrm{~h}$ to remove the chlorophyll completely. They were then placed on filter paper pads soaked with lactophenol for another $24 \mathrm{~h}$ to soften the leaf tissue and mounted in lactophenol-cotton blue for staining the conidia. Observations regarding unipolar and bipolar germination, number of germ tubes and number of appressorium formation were made under light microscope. All the experiments were conducted in triplicate and subjected to RBD for statistical analysis.

Experiments on detached pea leaves for disease development. This experiment was also conducted as stated above except leaves were floated on 2 percent sucrose solution in petri plate instead of sterilized distilled water. All the pre- and post-inoculation treated leaves including control were incubated for 24 and $48 \mathrm{~h}$ at $25 \pm 2^{\circ} \mathrm{C}$. Three leaves per treatment were taken and all the experiments were conducted in triplicate. Disease development was observed at each $48 \mathrm{~h}$ interval on each pea leaves in all cases for 14 days. Disease intensity was calculated by taking percent leaf area infected. All the experiments were conducted in triplicates.
Effect of nor-securinine on disease development of Erysiphe pisi on pea plants in pots in glasshouse. To check the effectiveness of the chemical under glasshouse conditions, the experiments were conducted in earthen pots $(20 \mathrm{~cm}$ dia.) The pots were filled with garden soil. Six seeds of pea were sown in each pot and kept in the glasshouse at $25 \pm 2^{\circ} \mathrm{C}$. Each replicate consisted of three pots. The lesion development was seen on 20-25-day-old pea (Pisum sativum) plants. Two treatments of the chemicals were given as pre- and post-treatments. Firstly, healthy plants were selected for pre- and post-inoculations along with the control. Then for pre-inoculation, chemical was sprayed with the help of a hand atomizer on selected plants. After $24 \mathrm{~h}$ the plants were seeded with $E$. pisi conidia by tapping heavily infected leaves on the adaxial surface of the leaves. For post-inoculation treatment, the plants were seeded with the conidia of E. pisi on adaxial surface of the leaves. After interval of $24 \mathrm{~h}$ different concentrations of chemicals were sprayed on the surface of leaves using a hand atomizer. The control experiments included only pea plants seeded with conidia of E. pisi. Disease development assessed was at each $48 \mathrm{~h}$ interval on each pea leaves in all cases for 26 days. Disease intensity was calculated by taking percent leaf area infected. All the experiments were conducted in triplicate.

Disease intensity, on a 0-4 scale, was calculated using the following formula-

Disease intensity (\%)

Sum of rating (0-4 scale)

Maximum possible score $\times$ No. of leaves observed $\times 100$.

The rating was done as: $0=$ No powdery mildew symptoms, $1=1 \sim 10 \%$ leaf area infected, $2=11 \sim 25 \%$ leaf area infected, $3=26 \sim 50 \%$ leaf area infected and $4=>51 \%$ leaf area infected.

\section{Results and Discussion}

The effect of nor-securinine on spore germination of some pathogenic fungi is shown at Table 1 . The sensitivity of different fungi varied considerably. Spore germination of Alternaria brassicae, Curvularia penniseti, Curvularia sp., Erysiphe pisi and Helminthosporium frumentacei was completely inhibited at 2,000 $\mu \mathrm{g} / \mathrm{ml}$ while only (39\%) germination was observed in A. solani. Similar effect was seen at $1,500 \mu \mathrm{g} / \mathrm{ml}$ in $H$. frumentacei. Spore germination of A. brassicae (4.0\%), C. penniseti (2.7\%) and E. pisi $(4.7 \%)$ was extremely low at $1,500 \mu \mathrm{g} / \mathrm{ml}$ while $A$. solani (66\%) and C. species (58\%) showed poor germination as compared to control at this concentration. Among all the tested fungi, C. species $(81 \%)$ and E. pisi $(13 \%)$ were less sensitive at minimum concentration $(1,000 \mu \mathrm{g} / \mathrm{ml})$ but 
Table 1. Effect of nor-securinine on spore germination of some fungi

\begin{tabular}{|c|c|c|c|c|c|c|}
\hline \multirow{2}{*}{ Fungus } & \multirow{2}{*}{ Host } & \multicolumn{5}{|c|}{ Spore germination (\%) } \\
\hline & & $\mathrm{C}$ & $1,000 \mu \mathrm{g} / \mathrm{ml}$ & $1,500 \mu \mathrm{g} / \mathrm{ml}$ & $2,000 \mu \mathrm{g} / \mathrm{ml}$ & $\mathrm{CD}$ \\
\hline Alternaria brassicae & Brassica campestris & 84 & $16^{\mathrm{a}}$ & $4.0^{\mathrm{b}}$ & $0.0^{\mathrm{b}}$ & 8.2 \\
\hline Alternaria solani & Solanum tuberosum & 96 & $82^{\mathrm{a}}$ & $66^{\mathrm{b}}$ & $39^{\mathrm{c}}$ & 12 \\
\hline Curvularia penniseti & Pennisetum typhoides & 92 & $36^{\mathrm{a}}$ & $2.7^{\mathrm{b}}$ & $0.0^{\mathrm{b}}$ & 14 \\
\hline Curvularia sp. & Imperata cylendrica & 92 & 81 & $58^{\mathrm{a}}$ & $0.0^{\mathrm{a}}$ & 14 \\
\hline Erysiphe pisi & Pisum sativum & 18 & 13 & $4.7^{\mathrm{a}}$ & $0.0^{\mathrm{a}}$ & 7.3 \\
\hline Helminthosporium frumentacei & Echinoclova frumentacum & 90 & $51^{\mathrm{a}}$ & $0.0^{\mathrm{b}}$ & $0.0^{\mathrm{b}}$ & 9.0 \\
\hline
\end{tabular}

Numbers with same superscript letters in rows are non-significant $(\mathrm{p} \leq 0.01) . \mathrm{C}=\mathrm{Control}, \mathrm{CD}=\mathrm{Critical}$ difference.

Critical difference (CD): Critical difference is used to find out those differences between the treatment means, which are significant. If any difference is equal to or greater than the critical difference, it will be declared as significant.

spore germination of other fungi such as $A$. brassicae (16\%), C. pennisetti (36\%), and H. frumentacei (51\%), was significantly inhibited. A. solani was found to be most resistant as its spores germinated even at $2,000 \mu \mathrm{g} /$ ml. A. brassicae, C. pennisetti and H. frumentacei were more sensitive than $A$. solani.

E. pisi showed sensitivity towards nor-securinine. There was a marked reduction in the germination of E. pisi conidia on excised pea leaves (Table 2). In preinoculation treatment, significant reduction in germination was observed $(60,38$ and $25 \%$ at $1,000,1,500$ and $2,000 \mu \mathrm{g} /$ $\mathrm{ml}$ while post-inoculation treatment yielded 88,58 , and $28 \%$ germination at the same concentrations, respectively. Maximum inhibition was recorded at $2,000 \mu \mathrm{g} / \mathrm{ml}$ when the leaves were pre-treated. Mostly unipolar conidial germination with one germ tube and bipolar with two germ tubes (one at each pole) occurred in all treatments. Unipo-

Table 2. Effect of nor-securinine on mode of germination of Erysiphe pisi conidia during pre-and post-inoculation treatments on detached leaves of Pisum sativum

\begin{tabular}{|c|c|c|c|c|c|c|c|}
\hline \multirow{3}{*}{$\begin{array}{l}\text { Concentration } \\
\qquad(\mu \mathrm{g} / m l)\end{array}$} & \multicolumn{6}{|c|}{ Germ tube formation (\%) } & \multirow{3}{*}{$\begin{array}{l}\text { Total } \\
(\%)\end{array}$} \\
\hline & \multicolumn{3}{|c|}{ Unipolar } & \multicolumn{3}{|c|}{ Bipolar } & \\
\hline & G1 & G2 & G3 & G1 & G2 & G3 & \\
\hline Control & 46 & 14 & 3.3 & 11 & 8.3 & 5.0 & 88 \\
\hline \multicolumn{8}{|c|}{ Pre-inoculation } \\
\hline 1,000 & $30^{\mathrm{a}}$ & $9.0^{\mathrm{a}}$ & 4.0 & 9.0 & 6.3 & $2.0^{\mathrm{a}}$ & $66^{\mathrm{a}}$ \\
\hline 1,500 & $23^{\mathrm{b}}$ & $7.3^{\mathrm{a}}$ & 1.7 & $3.7^{\mathrm{a}}$ & $1.3^{\mathrm{a}}$ & $1.0^{\mathrm{a}}$ & $38^{\mathrm{b}}$ \\
\hline 2,000 & $18^{\mathrm{b}}$ & $5.0^{\mathrm{a}}$ & $0.0^{\mathrm{a}}$ & $1.7^{\mathrm{a}}$ & $0.3^{a}$ & $0.0^{\mathrm{a}}$ & $25^{\mathrm{c}}$ \\
\hline \multicolumn{8}{|c|}{ Post-inoculation } \\
\hline 1,000 & 46 & 14 & 4.3 & 12 & 7.3 & 4.0 & 88 \\
\hline 1,500 & $36^{\mathrm{a}}$ & 9.3 & 3.0 & $5.0^{\mathrm{a}}$ & $4.0^{\mathrm{a}}$ & $2.0^{\mathrm{a}}$ & $58^{\mathrm{a}}$ \\
\hline 2,000 & $20^{\mathrm{b}}$ & $5.7^{\mathrm{a}}$ & $0.0^{\mathrm{a}}$ & $2.0^{\mathrm{a}}$ & $0.7^{\mathrm{a}}$ & $0.0^{\mathrm{a}}$ & $28^{\mathrm{b}}$ \\
\hline $\mathrm{CD}$ & 10 & 5.8 & 3.2 & 6.0 & 3.5 & 2.5 & 12 \\
\hline
\end{tabular}

Numbers with same superscript letters in rows are non-significant $(\mathrm{p} \leq 0.01) . \mathrm{C}=$ Control, $\mathrm{CD}=$ Critical difference, $\mathrm{G} 1=$ One germ tube, $\mathrm{G} 2=$ Two germ tubes, G3 $=$ Three germ tubes.

Critical difference (CD): Critical difference is used to find out those differences between the treatment means, which are significant. If any difference is equal to or greater than the critical difference, it will be declared as significant. lar germination with three germ tubes was completely inhibited in pre as well as post inoculation treatments at $2,000 \mu \mathrm{g} / \mathrm{ml}$, whereas unipolar germination with one and two germ tubes was significantly reduced in preinoculation as compared to postinoculation treatment at 1,000, 1,500 and $2,000 \mu \mathrm{g} / \mathrm{ml}$. Similarly, bipolar germination with three germ tubes at each pole was completely inhibited at $2,000 \mu \mathrm{g} / \mathrm{ml}$ in pre as well as postinoculation treatments. Whereas bipolar germination with one and two germ tubes at each pole was significantly reduced in both pre- as well as postinoculation treatments but pre-inoculation treatment at the same concentration showed greater efficacy (Table 2).

The number of appressoria was also affected significantly by nor-securinine. There was a marked reduction in appressorium formation in the germ tubes of E. pisi conidia on excised pea leaves. Maximum inhibition was recorded at 2,000 $\mu \mathrm{g} / \mathrm{ml}$. The appressorium formation was significantly reduced to 25,14 and $11 \%$ at $1,000,1,500$ and $2,000 \mu \mathrm{g} / \mathrm{ml}$, respectively, in preinoculation while in postinoculation treatment 37,20 and $12 \%$ at $1,000,1,500$ and $2,000 \mu \mathrm{g} / \mathrm{ml}$, respectively, was observed. Appressorium formation in bipolar germination having three germ tubes at each pole was completely inhibited at 2,000 $\mu \mathrm{g} /$ $m l$ in pre as well as postinoculation treatment, while significant reduction in appressorium formation in bipolar germination with two germ tubes at each pole in pre as well as postinoculation treatment. The number of appressoria in unipolar germination was not affected significantly in most of the cases, except that unipolar germination with two germ tubes was significantly reduced to 3 and $2.3 \%$ at 1,500 and $2,000 \mu \mathrm{g} / \mathrm{ml}$, respectively, in preinoculation treatment while $3 \%$ at $2,000 \mu \mathrm{g} / \mathrm{ml}$ in postinoculation treatment was observed (Table 3 ).

The disease intensity (D.I.) on detached leaves was taken up to $12^{\text {th }}$ day with an interval of 2 days. In total four readings were taken. There was a marked reduction in D.I. in vitro when plants were subjected to preinoculation treatment, which yielded $0.0,1.2,6.0$ and $12 \%$ at $1,500 \mu \mathrm{g} / \mathrm{ml}$ after each 2 day interval from $6^{\text {th }}$ day of inoculation, respectively. Although postinoculation treatment 
Table 3. Effect of nor-securinine on appressorium formation in Erysiphe pisi conidia during pre-and post-inoculation treatments on detached leaves of Pisum sativum

\begin{tabular}{|c|c|c|c|c|c|c|c|}
\hline \multirow{3}{*}{$\begin{array}{c}\text { Concentration } \\
(\mu \mathrm{g} / m l)\end{array}$} & \multicolumn{6}{|c|}{ Appressorium formation (\%) } & \multirow{3}{*}{$\begin{array}{l}\text { Total } \\
(\%)\end{array}$} \\
\hline & \multicolumn{3}{|c|}{ Unipolar } & \multicolumn{3}{|c|}{ Bipolar } & \\
\hline & G1A & $\mathrm{G} 2 \mathrm{~A}$ & G3A & G1A & $\mathrm{G} 2 \mathrm{~A}$ & G3A & \\
\hline Control & 14 & 7.0 & 2.0 & 2.3 & 8.3 & 6.3 & 39 \\
\hline \multicolumn{8}{|c|}{ Pre-inoculation } \\
\hline 1,000 & 12 & 3.0 & 2.3 & 2.0 & $3.0^{\mathrm{a}}$ & $2.3^{\mathrm{b}}$ & $25^{\mathrm{a}}$ \\
\hline 1,500 & 8.0 & $3.0^{\mathrm{a}}$ & 2.0 & 1.0 & $0.7^{\mathrm{a}}$ & $0.0^{\mathrm{c}}$ & $14^{\mathrm{a}}$ \\
\hline 2,000 & 6.3 & $2.3^{\mathrm{a}}$ & 0.0 & 2.0 & $0.3^{\mathrm{a}}$ & $0.0^{\mathrm{c}}$ & $11^{\mathrm{b}}$ \\
\hline \multicolumn{8}{|c|}{ Post-inoculation } \\
\hline 1,000 & 18 & 10 & 3.0 & 5.0 & $3.0^{\mathrm{a}}$ & $3.0^{\mathrm{a}}$ & 37 \\
\hline 1,500 & 11 & 3.3 & 2.3 & 2.0 & $2.0^{\mathrm{a}}$ & $1.0^{\mathrm{b}}$ & $20^{\mathrm{a}}$ \\
\hline 2,000 & 8.0 & $3.0^{\mathrm{a}}$ & 0.0 & 1.3 & $1.0^{\mathrm{a}}$ & $0.0^{\mathrm{c}}$ & $12^{\mathrm{b}}$ \\
\hline $\mathrm{CD}$ & 9.2 & 4.2 & 2.1 & 3.0 & 4.1 & 0.9 & 11 \\
\hline
\end{tabular}

Numbers with same superscript letters in rows are non-significant $(\mathrm{p} \leq 0.01) . \mathrm{C}=$ Control, $\mathrm{C} . \mathrm{D}=$ Critical difference, $\mathrm{G} 1=$ Appressoria in single germ tube, G2 = Appressoria in two germ tubes, G3 = Appressoria in three germ tubes.

Critical difference (CD): Critical difference is used to find out those differences between the treatment means, which are significant. If any difference is equal to or greater than the critical difference, it will be declared as significant.

yielded $0.0,2.0,8.0$ and $25 \%$ at the same concentration and incubation period, maximum reduction was noticed in preinoculation treatments at $2,000 \mu \mathrm{g} / \mathrm{ml}$, such as $0.0,0.0$,
1.2 and $2.0 \%$ only after $6^{\text {th }}, 8^{\text {th }}, 10^{\text {th }}$ and $12^{\text {th }}$ day, respectively while post-inoculation treatment yielded $0.0,1.0$, 4.2 and $11 \%$ respectively, at the same concentration and incubation periods (Table 4). In glasshouse, pre-inoculation treatment showed marked reduction in disease intensity $(0.0,0.0,2.0,5.0,7.4,13,17,22,27$ and $31 \%)$ at $1,500 \mu \mathrm{g} / \mathrm{ml}$ after each 2 day interval from $8^{\text {th }}$ day of inoculation. Although post-inoculation treatment yielded $0.0,1.0,3.0,6.2,11,19,26,35,39$ and $43 \%$ at the same concentration and incubation periods, maximum inhibition was recorded at $2,000 \mu \mathrm{g} / \mathrm{ml}$ when the leaves were pre-treated. Disease development completely inhibited for 14 days at $2,000 \mu \mathrm{g} / \mathrm{ml}$ in preinoculation treatment whereas it was only $3.0 \%$ in post-inoculation treatment. With the increase in days of treatment, efficacy of the chemical was found to be reduced but there was still marked reduction in disease intensity in pre and postinoculation treatments as compared to control. Preinoculation treatment at $2,000 \mu \mathrm{g} / \mathrm{ml}$ was found to be more effective for 16 days in reducing the D.I up to $0.5 \%$ while postinoculation treatment was also found to be effective for 14 days yielding $4.0 \%$ D.I. at the same concentration (Table 5).

The results of the present investigation indicate that plant alkaloid, nor-securinine, is highly effective against several phytopathogenic and saprophytic fungi including a biotroph. The fungi included in the present study belongs to two different groups but based on the activity of the

Table 4. Effect of nor-securinine on powdery mildew disease intensity on detached leaves of Pisum sativum during pre- and postinoculation treatments

\begin{tabular}{|c|c|c|c|c|c|c|c|}
\hline \multirow{3}{*}{$\begin{array}{c}\text { Period of } \\
\text { observation (Day) }\end{array}$} & \multirow{3}{*}{ Control } & \multicolumn{6}{|c|}{ Disease intensity (\%) } \\
\hline & & \multicolumn{3}{|c|}{ Pre-inoculation } & \multicolumn{3}{|c|}{ Post-inoculation } \\
\hline & & $1,000 \mu \mathrm{g} / \mathrm{ml}$ & $1,500 \mu \mathrm{g} / \mathrm{ml}$ & $2,000 \mu \mathrm{g} / \mathrm{ml}$ & $1,000 \mu \mathrm{g} / \mathrm{ml}$ & $1,500 \mu \mathrm{g} / \mathrm{ml}$ & $2,000 \mu \mathrm{g} / \mathrm{ml}$ \\
\hline $6^{\text {th }}$ & 0.5 & 0.0 & 0.0 & 0.0 & 0.2 & 0.0 & 0.0 \\
\hline $8^{\text {th }}$ & 9.2 & 2.2 & 1.2 & 0.0 & 4.2 & 2.0 & 1.0 \\
\hline $10^{\text {th }}$ & 35 & 14 & 6.0 & 1.2 & 25 & 8.0 & 4.2 \\
\hline $12^{\text {th }}$ & 84 & 67 & 12 & 2.0 & 77 & 25 & 11 \\
\hline
\end{tabular}

Table 5. Effect of nor-securinine on pea powdery mildew disease intensity in glasshouse during pre-and post-inoculation treatments

\begin{tabular}{|c|c|c|c|c|c|c|c|}
\hline \multirow{3}{*}{$\begin{array}{c}\text { Period of } \\
\text { observation (Day) }\end{array}$} & \multirow{3}{*}{ Control } & \multicolumn{6}{|c|}{ Disease intensity (\%) } \\
\hline & & \multicolumn{3}{|c|}{ Pre-inoculation } & \multicolumn{3}{|c|}{ Post-inoculation } \\
\hline & & $1,000 \mu \mathrm{g} / \mathrm{ml}$ & $1,500 \mu \mathrm{g} / \mathrm{ml}$ & $2,000 \mu \mathrm{g} / \mathrm{ml}$ & $1,000 \mu \mathrm{g} / \mathrm{ml}$ & $1,500 \mu \mathrm{g} / \mathrm{ml}$ & $2,000 \mu \mathrm{g} / \mathrm{ml}$ \\
\hline $8^{\text {th }}$ & 1.1 & 0.0 & 0.0 & 0.0 & 1.5 & 0.0 & 0.0 \\
\hline $10^{\text {th }}$ & 4.0 & 2.0 & 0.0 & 0.0 & 3.1 & 0.5 & 0.0 \\
\hline $12^{\text {th }}$ & 8.5 & 4.5 & 1.7 & 0.0 & 7.8 & 3.0 & 1.0 \\
\hline $14^{\text {th }}$ & 18 & 7.7 & 4.6 & 0.0 & 12 & 6.2 & 3.0 \\
\hline $16^{\text {th }}$ & 28 & 15 & 7.4 & 0.5 & 23 & 11 & 4.0 \\
\hline $18^{\text {th }}$ & 42 & 23 & 13 & 3.1 & 30 & 19 & 6.0 \\
\hline $20^{\text {th }}$ & 54 & 31 & 17 & 5.0 & 39 & 26 & 9.5 \\
\hline $22^{\text {nd }}$ & 62 & 35 & 21 & 6.4 & 53 & 35 & 12 \\
\hline $24^{\text {th }}$ & 68 & 43 & 27 & 8.0 & 57 & 39 & 15 \\
\hline $26^{\text {th }}$ & 75 & 48 & 31 & 10 & 64 & 43 & 20 \\
\hline
\end{tabular}


chemical it is at present difficult to conclude as to which group of fungi is most susceptible to this chemical as the number of fungi from different groups is very low. Hence, further detailed study on several members of other fungal groups will classify the specificity of efficacy.

Several plant products have shown good efficacy against several fungi both in vitro and in vivo. Alstovenine, a plant alkaloid from Alstonia venenata, was effective against pigmented and nonpigmented spores of several fungi. Conidia of Erysiphe sp. were very sensitive but spores of Fusarium udum were less sensitive to this alkaloid (Singh et al., 1999). In the present investigation similar trend of efficacy was seen. H. frumentacei and Erysiphe sp. were more sensitive to nor-securinine. It was observed that norsecurinine was highly effective in inhibiting spore germination, appressorium formation and in controlling powdery mildew of pea. Germ tube development and appressorium formation were faster at lower concentration. Singh et al. (2001) reported that the number of germ tubes of E. pisi determine the degree of infection by the pathogen in pea plants. The number of germ tube and appressorium formation were significantly reduced in both pre as well as post inoculation treatments at the test concentrations proving the efficacy of the nor-securinine. However, pre-inoculation treatment showed greater efficacy than postinoculation after $24 \mathrm{~h}$ of inoculation. Maximum inhibition occurred at 2,000 $\mu \mathrm{g} / \mathrm{ml}$. Although several alkaloids are already known to be antifungal (Maurya et al., 2001; 2002; Ahmed et al., 2004: Annapurna et al., 2004; Chung et al., 2004), such activity of the present chemical is being reported for the first time. As the chemical is highly effective even at low concentration $(1,000 \mu \mathrm{g} / \mathrm{ml})$, it is quite possible that this chemical may be successful in controlling other plant diseases under field conditions, but for better efficacy the chemical should be sprayed at 15 days of intervals for $2 \sim 3$ times. Results on the biological efficacy of nor-securine against some of fungi show the possibility of its utilization in field, which may be a substitute of chemical fungicides.

\section{References}

Ameer Basha, S., Mishra, R. K., Jha, R. N., Pandey, V. B. and Singh, U. P. 2002. Effect of berberine and ( \pm )-bicuculline isolated from Corydalis chaerophylla on spore germination of some fungi. Folia Microbiol. 47: 161-165.

Annapurna, J., Chowdary, I. P., Lalitha, G., Ramarrishna, S. V. and Ivengar, D. S. 2004. Antimicrobial activity of Euphorbia nivulia leaf extract. Pharm. Biol. 42: 91-93.

Ahmed, A. A., Hussein, T. A., Mahmoud, A. A., Farag, M. A., Pare, P.W., Wojcinska, M., Karchesy, J. and Marbry, T. J. 2004. Nor-ent-kaurane diterpenes and hydroxy lactones from Antennaria geyeri and Anaphalis margaritacea. Phytochemistry $\mathbf{6 5}$ : 2539-2543.

Asthana, A., Chandra, H., Dikshit, A. and Dixit, S. N. 1982. Vol- atile fungitoxicants from leaves of some higher plants against Helminthosporium oryzae. Z. pflanzenkrankh. Pflanzensch. 89: 475-479.

Atta-Ur-Rahman, R., Nasreen, A., Akhtar, F., Shekhani, M. S., Clardy, J., Parvez, M. and Choudhary, M. I. 1997. Antifungal diterpenoid alkaloids from Delphinium denudatum. J. Nat. Prod. 60: 474-475.

Chakravorty, D. K. and Pariya, S. N. 1977. Inhibition of phytopathogenic fungi in some Indian medicinal plant extracts. $Z$. Pflanzenkrankh. Pflanzensch. 84: 221-233.

Chung, P. Y., Chung, L. Y., Ngeow, Y. F., Goh, S. H. and Imiyabir, Z. 2004. Antimicrobial activities of Malaysian plant species. Pharm. Biol. 42: 292-300.

Evidente, A., Andolf, A., Abou-donia, A. H., Touema, S. M., Hammoda, H. M., Shawky, E. and Motta, A. 2004. (-)- amarbellisine, a lycorine type alkaloid from Amaryllis belladonna L. growing in Egypt. Phytochemistry 65: 2113-2118.

Kobayashi, K., Nishiro, H., Fukushima, M. and Tomita, H. 1987. Antifungal activity of pisiferic acid derivatives against rice blast fungus. Phytochemistry 26: 3175-3179.

Lyon, G. P., Reglinski, T. and Newton, A. C. 1995. Novel disease control compounds: the potential to immunize plants against infection. Plant Pathol. 44: 407-427.

Mahajan, V. M., Sharma, A. and Rattan, A. 1982. Antimycotic activity of berberin sulphate: an alkaloid from an Indian medicinal herb. Sabouraudia. 20: 79-81.

Maillard, M., Gupta, M. P. and Hosteltmann, K. 1987. A new antifungal prenylated fluronone from Erythrina berteroana. Planta Med. 53: 563-564.

, Hamberger, M., Gupta, M. P. and Hosteltmann, H. K. 1989. An antifungal isoflavonone from a structural revision of a flavonone of Erythrina berteroana. Planta Med. 55: 281-282.

Maurya, S., Srivastava, J. S., Jha, R. N., Pandey, V. B. and Singh U. P. 2001. Effect of tetrahydropalmatine, an alkaloid on spore germination of some fungi. Mycobiology 29: 142-144. and _. 2002. Efficacy of alka-

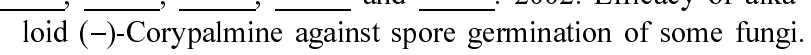
Folia Microbiol. 47: 287-290.

Manske, R. H. F. 1973. "The Alkaloids", vol xiv, pp. 489-491 Academic Press.

Mccarthy, P. J., Pitts, T. P., Gunawardana, G. P., Kelly, Borges M. and Pompani, S. A. 1992. Antifungal activity of meridine, a natural product from the marine sponge Corticium sp. J. Nat. Prod. 55: 1664-1668.

Mitul, G., Maurya, S., Pandey, V. B., Singh, V. P., Singh, A. K. and Singh, U. P. 2002. Effect of ent-norsecurinine, an alkaloid, on spore germination of some fungi. Mycobiology 30: 225-227

Prithiviraj, B., Singh, U. P., Khiste, S. and Ram, D. 1996. Effect of methanol extract of Aegle marmelos leaves on Sclerotium rolfsii. Internat. J. Pharm. 34: 148-150.

Manickam, M., Singh, U. P. and Ray, A. B. 1997a. Antifungal activity of anacardic acid, a naturally occuring derivative of salicylic acid. Can. J. Bot. 74: 207-211.

, Singh, U. P., Manickam, M., Srivastava, J. S. and Ray, A. B. 1997b. Antifungal activity of bergenin, a constituent of Fluggea microcarpa. Plant Pathol. 46: 244-248.

Singh, K. P. and Schumacher, K. P. 1998. Field evaluation of ajoene, a constituent of garlic (Allium sativum) and neemazal, a product of neem (Azadirachta indica), against powdery mildew (Erysiphe pisi) of pea (Pisum sativum) $Z$. 
pflanzenkrankh. Pflanzensch. 105: 274-278.

Reimers, F., Smolka, S. E., Wemens, S., Schumacher, K. P. and Wagner, K. G. 1993. Effect of ajoene, a compound derived from Allium sativum, on phytopathogenic and epiphytic microorganisms. J. Plant Dis. Prot. 100: 622-633.

Sarma, B. K., Srivastava, J. S., Prithiviraj, B., Singh, U. P. and Pandey, S. N. 1998. Effect of Mannich bases on some plant pathogenic fungi. Folia Microbiol. 43: 393-398.

, Pandey, V. B., Mishra, G. D. and Singh, U. P. 1999. Antifungal activity of berberine iodide, a constituent of Fumaria indica. Folia Microbiol. 44: 164-166.

Singh, U. P., Pandey, V. B., Singh, K. P. and Singh, R. D. N. 1988. Antifungal activity of some new flavonone and flavone glycosides of Echinops echinatus. Can. J. Bot. 66: 1901-1903.

, Pandey, V. N., Wagner, K. G. and Singh, K. P. 1990. Antifungal activity of ajoene, a constituent of garlic (Allium sativum). Can. J. Bot. 68: 1354-1356.

, Singh, K. P., Tripathi, V. K. and Pandey, V. B. 1994. Antifungal activity of some naturally occurring plant alkaloids. Intrenat. J. Trop. Plant Dis. 12: 209-212.

, Prithiviraj, B., Wagner, K. G. and Schumacher, K. P. 1995. Effect of ajoene, a constituent of garlic (Alium sativum) on powdery mildew (Erysiphe pisi) of pea (Pisum sativum). $J$.
Plant Dis. Prot. 102: 399-406.

Singh, S. K., Sarma, B. K., Srivastava, J. S., Singh, U. P. and Ray, A. B. 1999. Antifungal activity of $\phi^{3}$-Alstovenine, a plant alkaloid isolated from Alstonia venenata. Folia Microbiol. 44: 510-512.

Singh, U. P., Sarma, B. K., Mishra, P. K. and Ray, A. B. 2000. Antifungal activity of venenatine, an indole alkaloid isolated from Alstonia venenata. Folia Microbiol. 45: 173-176.

Basha, S. A., Srivastava, C. P. and Sarma, B. K. 2001. Mode of germination of Erysiphe pisi conidia as criteria for assessing degree of resistance in pea cultivars. Z. Pflanzenkrh. 108: 472-476.

Singh, B., Srivastava, J. S., Khosa, R. L. and Singh, U. P. 2001. Individual and combined effects of berberine and santonin on spore germination of some fungi. Folia Microbiol. 46: 137142.

Srivastava, B. P., Singh, K. P., Singh, U. P. and Pandey, V. B. 1994. Effect of some naturally occuring alkaloids on conidial germination of Botrytis cinerea. Bioved. 5: 69-72.

Vollekova, A., Kostalova, D. and Sochorova, R. 2001. Isoquinoline alkaloids from Mahonia aquifolium stem bark are active against Malassezia species Folia Microbiol. 46: 107-112. 